\title{
Effect of Obstacles and Horizontal Wind on the Fire Behavior inside Engine Compartment of Motorcoach
}

\author{
Dongmei Huang ${ }^{1,2, *}$, Xinqun Wang ${ }^{1}$ and Chenning Guo ${ }^{1}$ \\ ${ }^{1}$ College of Quality and Safety Engineering, China Jiliang University, Hangzhou, Zhejiang, 310018, China \\ ${ }^{2}$ Key Laboratory of Furniture Inspection Technology of Zhejiang Province, Hangzhou, Zhejiang, 310018, China \\ *Corresponding author
}

\begin{abstract}
Engine compartment forms often a geometrical complex and is filled with a variety of combustible materials. In this paper, two groups of half scale fire experiments were conducted to investigate the fire behavior in the engine compartment of a motorcoach under different conditions. In the first experiment group, the obstacles made of iron boxes and pipes, arranged accordingly to the actual structure of a motorcoach engine compartment, were placed inner the experimental apparatus and a liner type fire source was adopted. In the second experimental group, the pool fire was used and the horizontal wind underneath the apparatus was added. Measurements of interior temperatures with different diameter thermocouples were performed. Standard video and static photograph were recorded. The temperature measured in the experiments was compensated by the first order method. Results showed that the pool fire and wick-type oil-burning formed both on the obstacles' surface and ground greatly prolonged the burning time. The horizontal wind underneath the engine compartment remarkably enlarged the flame size and changed its shape. We recommend that oil leakage to the equipment surface and using thermoplastic materials in engine compartment should be avoided. In the case of fire the motorcoach engine should be turned off immediately.
\end{abstract}

Keywords-motorcoach fire; engine compartment; obstacle; horizontal wind; thermoplastic material; wick-type oil-burning

\section{INTRODUCTION}

Motorcoach fires usually spread rapidly and consume a motorcoach within 15 to 20 minutes, causes the serious consequences ${ }^{1}$. In China, motorcoache suffer from fire incident every year $^{2,3}$. A recent example is the tragic motorcoach fire near Zhaoyuan, China in November 28, 2009 which killed 10 people. The fire started in the engine compartment due to the fact that combustible materials which covered on the engine surface were heated to its auto-ignition temperature. Another example of a motorcoach fire was in Shanghai on May 5, 2008 in which 12 passengers were killed. According to Neil R. Meltzer's report ${ }^{4}$, the frequency of motorcoach fires may be as high as six per day in the United States. Even if there are no fatalities in motorcoach fires, complete loss of the coach and passenger properties is usually a typical one.

The most common origin location of motorcoach fire is the engine compartment, which is often a geometrical complex. Fires may occur for several reasons. Some equipment, such as the manifold, turbocharger, engine components and braking system in engine compartment may reach temperature high enough to cause ignition of the combustible materials. Fires may also occur because of short circuits in electrical wiring. Rolf Hammarström et. $\mathrm{al}^{5}$ have developed small engine compartments $\left(1-5 \mathrm{~m}^{3}\right)$ to study the behavior of different types of fires, such as smoldering, re-ignition, fire at different locations, and oher properties influencing the extinguish capacity. Furthermore, most of other investigations concern motorcoach fires were relevant to the passenger compartment, such as combustion properties of materials, smoke control systems and fire penetration from outside to inside ${ }^{6-11}$.

Previous studies have done little to relate the effect of obstacles and horizontal wind underneath the engine compartment on the fire behavior. The absence of such phenomenon is an impediment to the understanding and prevention from fires started from an engine compartment. Thus the main objective of this study is to investigate the fire behavior within engine compartment of a motorcoach vehicle with the consideration of the effect of obstacles and horizontal wind on the process, using a half scale experimental apparatus.

\section{EXPERIMENTAL SETUP}

The experimental apparatus can be seen in Figure 1(a). It consisted of an engine compartment part and an air tunnel. The engine compartment was a steel frame of $1.25 \mathrm{~m}$ in length, 1.25 $\mathrm{m}$ in width and $1.1 \mathrm{~m}$ in height, covered by $8 \mathrm{~mm}$ thick fireproof boards. There was an observation window on one side and a door on the other side. To simulate the horizontal wind during the motorcoach traveling state, an air tunnel of $1.25 \mathrm{~m}$ in length, $1.25 \mathrm{~m}$ in width and $0.2 \mathrm{~m}$ in height was connected with an air supply apparatus underneath the engine compartment part. There were also two fireproof boards of 1.25 $\mathrm{m}$ in length, $8 \mathrm{~mm}$ thick and $0.2 \mathrm{~m}$ in height on the left and right side of the air tunnel. The air supply apparatus consisted of two axial flow fans with the type of FZY-4E500 and a trapezoidal air outlet. In order to rectify the wind flow, a porous plate was placed at the junction of the air outlet and air tunnel. The Froude modeling ${ }^{12}$ was applied to build up the physical model with a scale ratio of 1:2. By keeping the Froude number constant, the relationships could be simplified to obtain the required scaling laws. The velocity, $\mathrm{V}$, in the air tunnel was scaled using $\mathrm{V}_{\mathrm{m}} / \mathrm{V}_{\mathrm{f}}=\left(\mathrm{L}_{\mathrm{m}} / \mathrm{L}_{\mathrm{f}}\right)^{0.5}$. Where: $\mathrm{L}$ denotes the size, and the subscript ' $m$ ' represents the experimental apparatus and the subscript ' $f$ ' represents the full-scale engine compartment. The wind velocity under actual condition was assumed to be 30 
$\mathrm{km} / \mathrm{h}$, and the model velocity was $5.89 \mathrm{~m} / \mathrm{s}$. In our experiment the velocity of $6 \mathrm{~m} / \mathrm{s}$ was adopted.

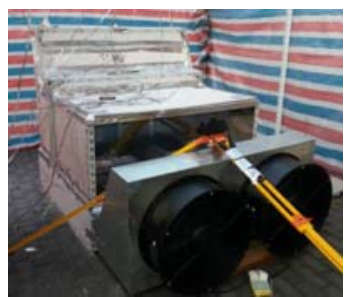

(A) GENERAL PATTERN

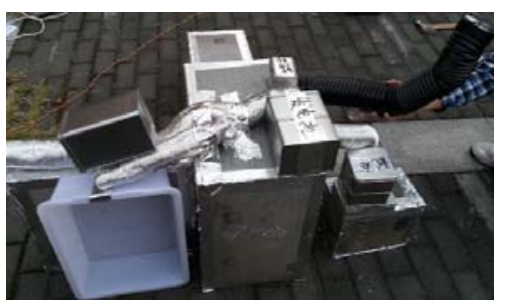

(B)OBSTACLE
FIGURE I. SCHEME OF EXPERIMENTAL APPARATUS.

According to Meltzer's report ${ }^{1}$, the major fuels in the engine compartment of a motorcoach are lubricating oil, transmission fluid, diesel fuel on or around the equipments, and other solid combustible materials, such as intake manifold, cables and so on. There are many devices located in the engine compartment. To investigate the fire behavior on and around these devices, obstacles made from $1 \mathrm{~mm}$ thick noncombustible iron boxes and pipes were arranged according to the actual structure and placed in the experiment stand. The combustible materials such as lubricating oil, diesel fuel, combustible pipes were distributed on and around the surface of obstacles is shown in Figure 1(b).

In the experiments, two types of fire sources were adopted. The first one was simulated by a $0.6 \mathrm{~m}$ length, and $0.5 \mathrm{~cm}$ in diameter hemp rope, which absorbed the diesel and alcohol mixture. Hemp rope was placed on the surface of the obstacles. The second one was a diesel pool fire with the diameter of 18 $\mathrm{cm}$. The fuel volume in each experiment was equal to $250 \mathrm{ml}$ (240 $\mathrm{ml}$ diesel and $10 \mathrm{ml}$ alcohol) before ignition.

Temperature was measured inside the experiment apparatus at different locations. K-type thermocouples (TCs) were used for that purpose. The approximate locations of TCs are presented in Figure 2. The diameter of TCs 1-8, TCs 9-12 and TCs $13-17$ was $3 \mathrm{~mm}, 2 \mathrm{~mm}$ and $1 \mathrm{~mm}$, respectively. Thetemperature measured by different diameter thermocouples was compensated before analyse by using the first order method. A standard video recording was located at the position facing the observation window. The main purpose of the temperature measurements and video recorder was to monitor the progress of flame spread, and identify the effect of obstacles and wind on the fire behavior in the device. The wind velocity at a height of $0.1 \mathrm{~m}$ above the ground of the tunnel at different locations, was measured by a hot-wire anemometer. The velocity was the average value of each point.

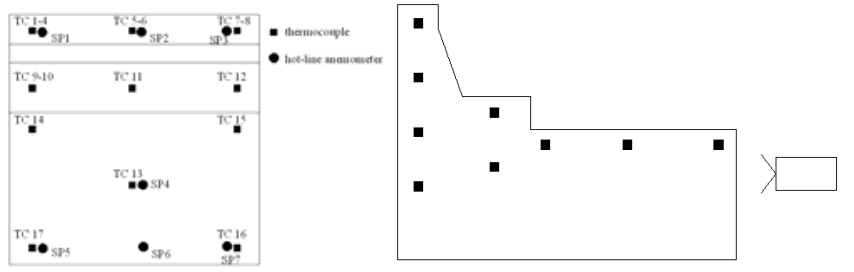

FIGURE II. A DIAGRAM OF THERMOCOUPLES LOCATION
Two test groups were conducted in the course of investigation. In the first group (test 1 and 2), a linear type ignition source was adopted and the obstacles were both taken into consideration, the difference between the two tests was the place and the ignition point of the fire source. In the second group (test 3 and 4), the diesel pool was adopted, while the obstacles were removed and the wind underneath the experimental apparatus with a speed of about $6 \mathrm{~m} / \mathrm{s}$ was added after ignition. After each test, a comparatively long period was needed to cool down the apparatus. Therefore, the ambient temperature might have been several degrees different at the four different test times. Detailed parameters of the four tests are summarized below.

\section{RESUlTS AND DiscUSSIONS}

\section{A. Flame spread on the obstacles}

In order to study the fire behavior on the obstacles' surface in the engine compartment, some iron boxes with a variety of fuels on and around their surface were placed in the experimental apparatus. The compensated temperature profiles at different fire source locations can be seen in Figure 5. The time was count from the moment of hemp rope ignition. A towel absorbed alcohol was used to start the fire.

From Figure 3 (a) we can see that temperature at TC1 and TC5 reaches the maximum, approximately $1100 \mathrm{~K}$ after ignition, and maintains at a constantly high level before $180 \mathrm{~s}$ and $500 \mathrm{~s}$, respectively. And temperature at TC11 peaked at $300 \mathrm{~s}$, then decreases sharply. All the temperatures except TC14 and TC15 first increase and then decrease subsequently, and it maintains low level after about $500 \mathrm{~s}$.

Figure 3 (b) shows an entirely different result when the fire source was moved from the left side to the right part. Only temperature at TC5 rises to about $900 \mathrm{~K}$ at $180 \mathrm{~s}$, and sustains about $40 \mathrm{~s}$, then decreases sharply. In particular, all TCs increase suddenly. Temperatures at TCs1-3, TC9 and TC13 haven't gone up until $250 \mathrm{~s}$.

To explain the temperature change during the two experiments, the experimental process needs to be reviewed. Figure 4 supplies a snapshot of the two tests at various times. As it can be seen, the fuels in the front part of apparatus were not ignited throughout the process of the two experiments. Flame was mainly located on the obstacles' surface in the rear part of apparatus. This is why the rear temperatures such as TC1, TC5 are higher than the front ones. Temperature at some TCs such as TC1 and TC5 on test 1 and TC5 on test2 increased sharply, because they were in the flame zone. And with the pulsations of flame, temperature at these TCs intensively fluctuated.

In addition, from Figure 4(a) we could also see that from about $580 \mathrm{~s}$ to the end, flame existed only on the obstacles' surface at the left side, and flame size decreased gradually. It was a wick-type oil-burning formed by combustion ash dropping onto the obstacles' surface and sucked out lubricating and diesel oil or coolant, then ignited and burnt slowly over a long period of time. With the decreased of the amount of oil, the flame was getting smaller until the oil was the oil exhausted. 


\section{B. Effect of horizontal wind}

The flame structure of diesel oil pool fire in calm wind and with $6 \mathrm{~m} / \mathrm{s}$ horizontal wind underneath engine compartment in the stable stage conditions is shown in Figure 8. It shows that the flame height or size in the horizontal wind condition is remarkably enlarged compared to that in calm wind condition. The height and length of the flame zone under the horizontal wind condition reaches to more than $60 \mathrm{~cm}$ and $80 \mathrm{~cm}$, respectively, while it is only approximately $50 \mathrm{~cm}$ and $23 \mathrm{~cm}$ in the calm wind condition. According to Babrauskas, ${ }^{18}$ results, fire in the calm wind condition belonged to the convectively dominated burning. While with the effect of wind the turbulence intensity of flame increases, and the radiative regime is obtained. From Figure 5 (b), we can see that the flame grows in an anticlockwise spiral like a fire whirl. In addition, the flame front develops toward left side.

TABLE I. SUMMARY OF PARAMETERS OF TEST SERIES.

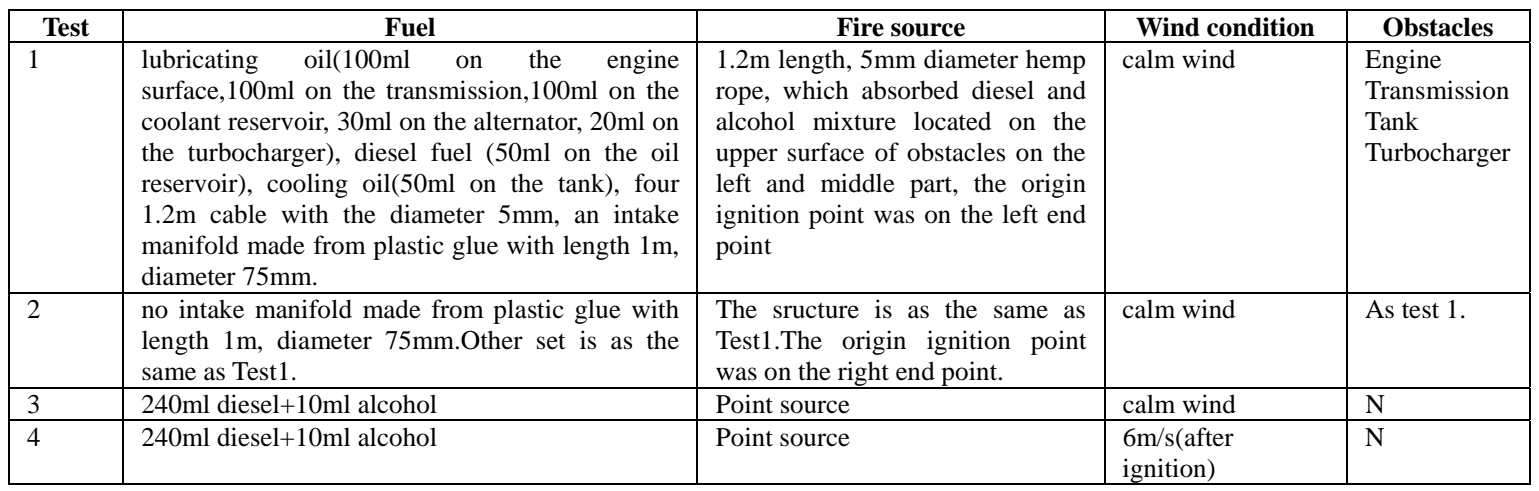
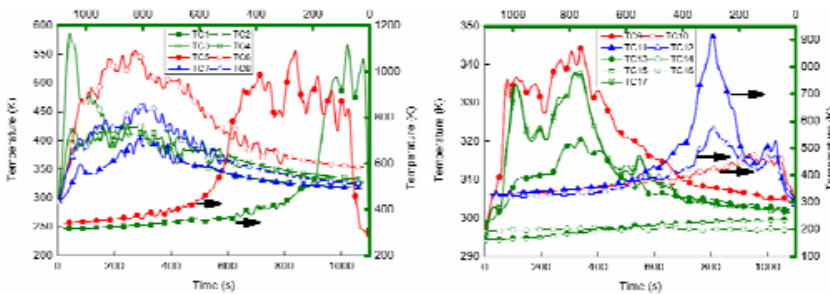

(A) FIRE SOURCE ON THE LEFT SIDE TC1-TC8 AND TC9-TC17
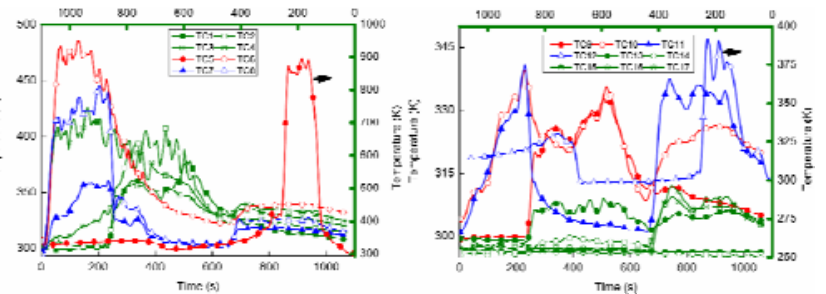

(B) FIRE SOURCE ON THE RIGHT SIDE TC1-TC8 AND TC9-TC17

FIGURE III. THE COMPENSATED TEMPERATURE PROFILES AT DIFFERENT FIRE SOURCE.

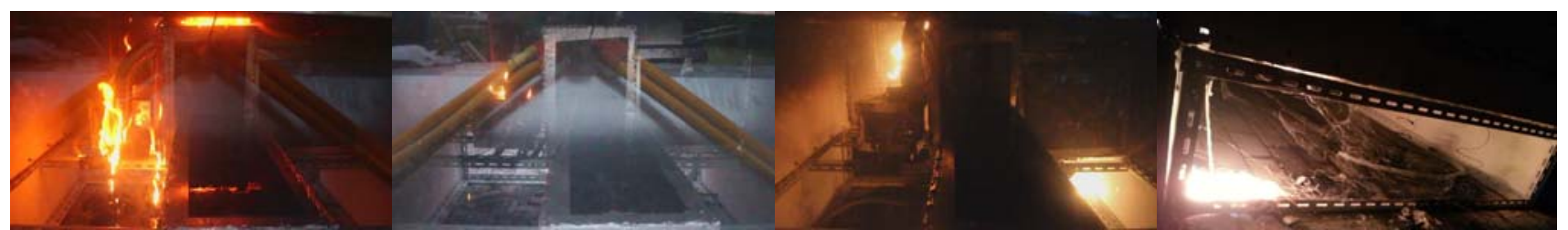

(A) TEST 1 326S

$586 \mathrm{~S}$

(B) TEST 2 680S

800S

FIGURE IV. PHOTOGRAPHS OF THE EXPERIMENTAL PROCESS AT VARIOUS TIMES.

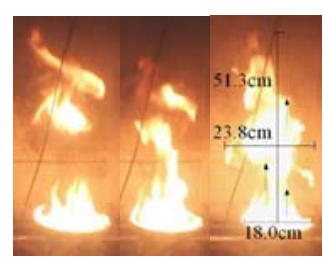

(A) CALM WIND

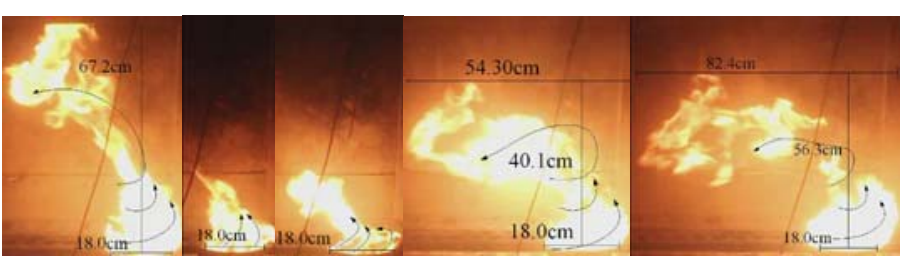

(B) HORIZONTAL WIND

FIGURE V. PHOTOGRAPH OF THE FLAME STRUCTURE IN THE STABLE COMBUSTION STAGE.

The temperature profiles in the engine compartment at different points are shown in Figure 6. We can see that the temperature at TC1 reaches the maximum, approximately 850 $\mathrm{K}$ about $250 \mathrm{~s}$ after ignition, and sustains about $200 \mathrm{~s}$, then 
decreases gradually. And there is a steady-state phase during $200 \mathrm{~s}$ to $600 \mathrm{~s}$ at TC9, TC13 and TCs16-17 due to the smoke layer which stabilizes at about $20 \mathrm{~cm}$ height below the front part top of the engine compartment. During the experiment, we could see a clear interface between the smoke layer and air layer. Under the horizontal wind condition, the overall temperature in the engine compartment was much lower than
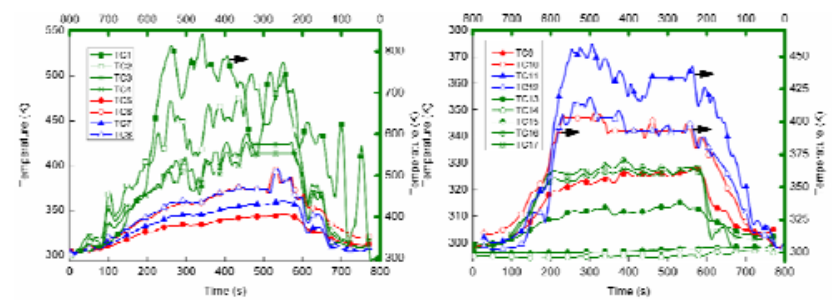

(A) CALM WIND that in the calm wind condition and the smoke movement become disordered. It might be like that because the horizontal wind was benefitial to smoke exhaust and disrupted its movement. However, the horizontal wind was extremely dangerous in the case of motorcoach fire as it than enlarged the flame size.

FIGURE VI. TEMPERATURE PROFILES WITH AND WITHOUT THE EFFECT OF HORIZONTAL WIND.

\section{CONCLUSION}

A half scale experimental stand was designed to investigate the effect of obstacles and horizontal wind on the fire behavior inside engine compartment of motorcoach. Before the experiments, temperatures measured by different diameter thermocouples was compensated by the first order method.

Results confirmed that under such conditions a pool fire could be performed due to the thermoplastic materials melting during the combustion. It also could form the wick-type oilburning when combustion residue fell into oil. Those two types of fire could sustain the combustion for a long period of time, and continuously heating the space.

The horizontal wind underneath the engine compartment could remarkably enlarge the flame size and change its shape. The flame grown in an anticlockwise spiral likes a fire whirl. The overall temperature in the engine compartment decreased in the presence of horizontal wind.

This work could be useful for the design and the daily maintenance and management of engine compartment of motorcoach. It was suggested that thermoplastic materials used in engine compartment of motorcoach should be avoided and the oil on the equipment surface should be clean up in time. To avoid the flame enlarge process the vehicle must be stopped immediately when the fire is recognized. Further researches into the different horizontal wind speed and preheating of equipment on the fire behavior are still needed.

\section{ACKNOWLEDGMENT}

This work was supported by the National Natural Science Foundation of China, No. 51306168, and the International Science \& Technology Cooperation program of China, No. 2013DFG71760. The authors thankfully acknowledge the support.

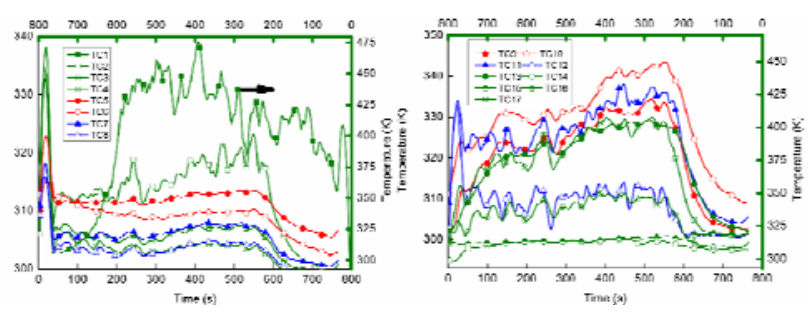

(B) HORIZONTAL WIND

\section{REFERENCES}

[1] N. Meltzer, G. Ayres, and M. Truong, Motorcoach Fire Safety Analysis, Federal Motor Carrier Safety Asministration Vehicle and Roadside Operations Division, 2009.

[2] C. Y. Yang, X. W. Wu, and X. W. Su, “ Flow field character of arson fire in a bus,” Fire Science and Technology, vol. 30(2), pp. 95-99, 2011.

[3] Y. F. Sun, M. Sun, H. G. Liu, and X. Pan, "Investigation on a maj or bus burning acciden”, Fire Science and Technology. 10rd ed, vol. 30, pp. 977-979, 2011.

[4] N.R. Meltzer, G. Ayres, and M.Truong, "Motorcoach Fire Safety Analysis: The Causes, Frequency, and Severity of Motorcoach Fires in the United States, National Transportation Systems Center, U.S. Department of Transportation Research and Innovative Technology Administration: Cambridge, Massachusetts. United States, 2012.

[5] R. Hammarström, J. Axelsson, M. Försth, and P. Johansson, Sundström B. Bus fire safety. SP Report, Norwegian Public Roads Administration,Swedish Road Administration, SP Technical Research Institute of Sweden, vol. 41,2008.

[6] M. Försth, H. Modin, and B. Sundström, "A comparative study of test methods for assessment of fire safety performance of bus interior materials,” Fire and Materials.5rd ed. vol. 37, pp. 350-357, 2013.

[7] E. Johnsson, and J. C.Yang, "Experimental study on tire fire penetration into a motorcoach passenger compartment," Fire and Materials. 1rd ed, vol. 38, pp. 63-76, 2014.

[8] EL Johnsson. Motorcoach Flammability Project Final Report: Tire FiresPassenger Compartment Penetration, Tenability, Mitigation, and Material Performance, National Institute of Standards and Technology, 2010.

[9] K.C. Lam, W.K. Chow, and Y. Gao, “ Numerical simulation for doubledeck bus fires," in Progress in Safety Science and TechnologyProceedings of 2006 International Symposium on Safety Science and Technology, pp. 629-631, 2006.

[10] W. K. Chow, K. C. Lam, and N. K. Fong, H. Dong, G. W. Zou, and Y. Gao, “ Scale Modelling Results on Smoke Spreading and Control in a Double-Deck Bus,” International Journal on Engineering PerformanceBased Fire Codes, 4rd ed, vol. 8, pp. 145-151, 2006.

[11] W. K. Chow, “ Flashover for bus fires from empirical equations,” Journal of fire sciences.,1rd ed, vol. 19, pp. 81-93, 2001.

[12] A.C Carey, "Scale modeling of static fires in a complex geometry for forensic fire applications,” University of Maryland, 2010.

[13] M.V. Heitor, and A. L. N Moreira, "Thermocouples and sample probes for combustion studies,” Progress in Energy and Combustion Science, 3rd ed, vol. 19, pp. 259-278,1993. 
[14] L. G. Blevins, and W. M. Pitts, "Modeling of bare and aspirated thermocouples in compartment fires," Fire Safety Journal. 4rd ed, vol. 33, pp. 239-259, 1999.

[15] M. Tagawa, and Y. Ohta, “ Two-thermocouple probe for fluctuating temperature measurement in combustion-Rational estimation of mean and fluctuating time constants," Combustion and Flame. 4rd ed, vol. 109, pp. 549-560, 1997.

[16] D.Q. Nguyen, R. Fedkiw, and H. W. Jensen, “ Physically based modeling and animation of fire," ACM Transactions on Graphics (TOG), 3rd ed, vol. 21, pp. 721-728, 2002.

[17] K. Shannon, and B. Butler, "A review of error associated with thermocouple temperature measurement in fire environments. in Second international wildland fire ecology an fire management congress and fifth symposium on fire and forest meteorology," American Meteorological Society, Orlando, FL, 2003.

[18] V. Babrauskas, "Estimating large pool fire burning rates," Fire Technology. 4rd ed, vol. 19, pp. 251-261, 1983. 